\title{
MATH REVIEWS NEWS
}

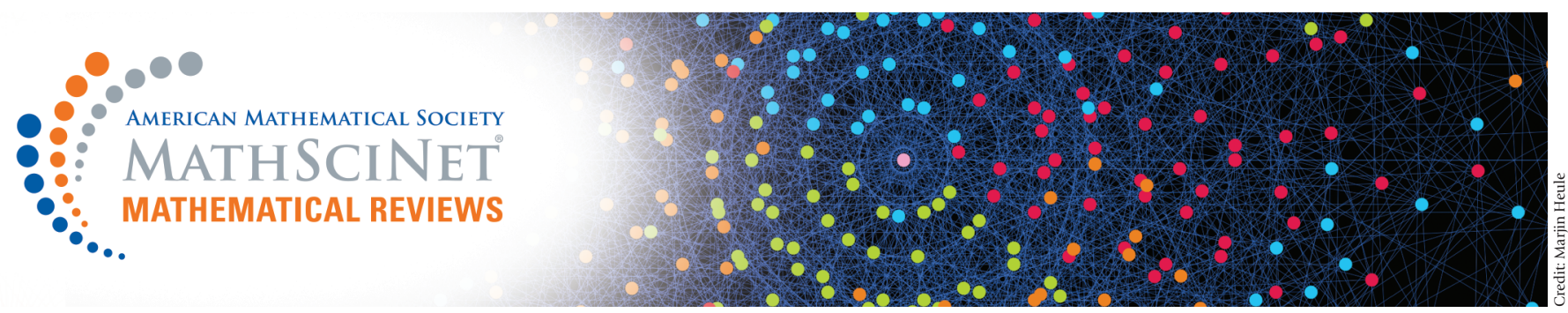

\section{Jane Kister: Executive Editor Extraordinaire}

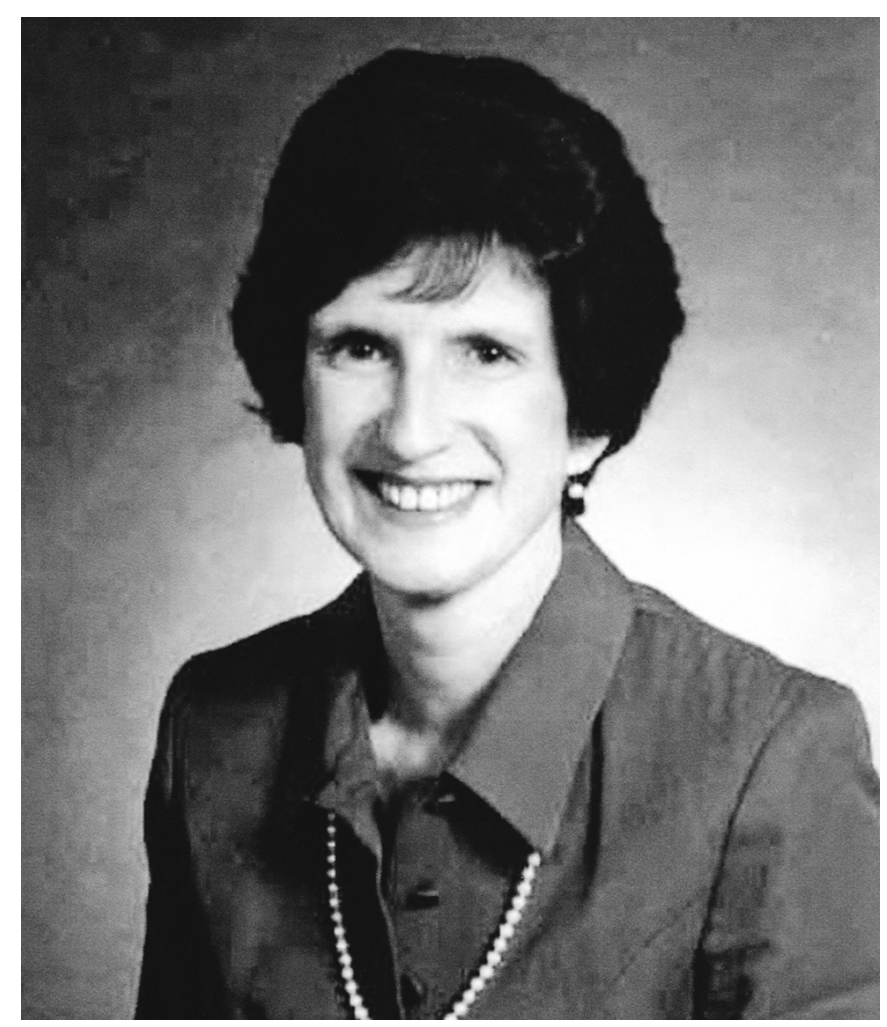

Jane Kister

\section{Edward Dunne}

Jane Kister, former executive editor at Mathematical Reviews, died December 1, 2019, at the age of seventy-five. Jane was an editor at Mathematical Reviews from 1979 to 2004 , starting as an associate editor, then moving to associate executive editor in 1984 . She was executive editor from 1998 to her retirement in 2004, which was an important period just after the release of MathSciNet in 1996. Jane was the first woman to become executive editor, as well as the first to have been promoted from within the ranks of Math Reviews editors. Jane received her D.Phil. from Oxford University in 1972. Her thesis supervisor was Robin Gandy, who was a student of Alan Turing. She had a tenured faculty position at Oxford before coming to Ann Arbor. As a researcher, her mathematical specialty was logic and foundations of mathematics. While working at Math Reviews, Jane was also an editor of the $\Omega$-Bibliography of Mathematical Logic. By a strange coincidence, I was her in-house editor at Springer-Verlag, which is how I first came to meet her in Gert Müller's office at the University of Heidelberg.

Jane was talented and kind. She was well liked by everyone at Mathematical Reviews (MR), and by the many throughout the AMS who knew her. She was also very good at what she did. When I became executive editor, I met several times with Jane, who gave me lots of excellent advice.

Edward Dunne is the executive editor of Mathematical Reviews at the American Mathematical Society. His email address is egd@ams .org.

For permission to reprint this article, please contact: reprint-permi ssion aams.org.

DOI: https://dx.doi.org/10.1090/noti 2096 
She came to MR social gatherings whenever she could, and was always glad to see how Mathematical Reviews was doing. She enjoyed catching up with old friends, as well as meeting new people.

Two recurring themes in tales of Jane and her husband, Jim, are their hospitality and their appreciation for fine wine. When Smilka Zdravkovska, a former associate editor at Mathematical Reviews, first met the Kisters, a fine dinner was planned with Smilka and Andrew Ranicki, who happened to be visiting Ann Arbor. A severe thunderstorm had knocked out the electricity, causing dinner to be takeout pizza, but Jane and Jim made sure to serve a nice Bordeaux with it. Smilka got to know Jane well, and remarked, "Jane was an excellent speaker but an even better listener. She would always ask questions about all the members of the circle of family and friends of her interlocutor. And she would remember the answers the next time you met her. This I think she inherited from her mother." Asen Dontchev, another former associate editor, recalled walking to lunches with Jane and others from the Math Reviews office. He wrote, "There was a rule not to talk about work during lunch, but every rule is broken, as a rule." On the way back, Jane would often stop or take detours to admire particularly splendid trees in the neighborhood. Ann Arbor, the City of Trees, clearly suited Jane.

Jim Kister, who was a leading topologist at the University of Michigan, died a year before Jane. After Jim's death, Jane took a friend's advice and never said no to an offer to go out to meet someone. I saw a lot of Jane in that last year.

Allyn Jackson wrote a very informative article about Jane Kister on the occasion of her becoming executive editor [Notices Amer. Math. Soc. 45 (1998), no. 7, 877-878]. What follows are some reminiscences from people who knew Jane well.

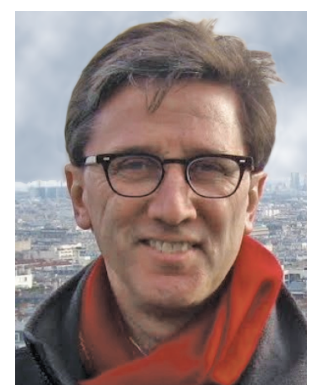

Edward Dunne

\section{Peter Hinman}

Jane Kister and I were both logicians, so in principle we had a close professional relationship, although she was a proof theorist and I a recursion theorist. Consequently, our interests overlapped only tangentially. In recent years, our relationship was largely social.

I first met Jane (at the time, Jane Bridge) in 1971 while she was at Oxford and had organized a small conference that I attended. We next crossed paths in 1977 when she was a visitor for the Winter Semester at Heidelberg, where I was visiting for the year 1976-77. There we saw each other several times a week, particularly at the logic seminar.

The most important outcome of that year stemmed from a visit of my good friend Jim Kister in May or June on his way to Greece. I'm not sure whether or not Jane was still in Heidelberg at the time and I don't think they met there, but since Jim was planning a sabbatical visit to Oxford in the fall, I alerted him to Jane's presence there. The rest is history!

After their wedding, a small family affair in England, when they returned to Ann Arbor, my wife at the time and I hosted a reception for Jim's and soon to be Jane's Ann Arbor friends. It was a splendid party with dueling galantines of goose (my wife and I couldn't agree on the presentation) and, of course, excellent wine.

Over the years, Jim and Jane were my most steadfast friends. I got to know Jane's parents quite well over the years, both during their visits to Ann Arbor and in a couple of my visits to London.

When my second wife, Elizabeth, was diagnosed with leukemia in the fall of 2008 while we were on sabbatical in London, we returned to Ann Arbor for a long and complicated treatment that ended with her death in September 2009. Through it all, Jim and Jane were always there for me when I (often) needed them. It was full circle, since I had left their house after drinks with them and Jane's parents, Nigel and Margaret, on New Year's Eve in 1981 for my first date with Elizabeth.

As Jim became less physically mobile (but never less mentally mobile!), Karen (my current partner) and I tried to help Jane as much as she would allow, but her stiffupper-lip British pride sometimes got in the way. After Jim died, we invited Jane for dinner most every week when we were in town and I think were of some help getting her along the path of starting a new life that sadly never had time to fully materialize.

Although Jane abandoned mathematical research soon after coming to Ann Arbor, she did continue for many years to attend the logic seminar that Andreas Blass and I ran at the University of Michigan. And she-and also usually

Peter Hinman is professor emeritus of mathematics at the University of Michigan. His email address is pgh@umich.edu. 
Jim-participated enthusiastically in the after-seminar traditions of turkey and bagels or pizza at one of our homes. We didn't often talk on mathematical themes-usually bits of Math Reviews politics from her or University of Michigan departmental gossip from me-but of course our shared mathematical connections were always underlying our friendship. I have been an MR reviewer for fifty years and I treasured the compliments that Jane occasionally gave for a review of mine that she had read.

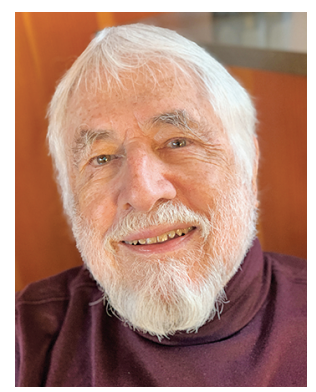

Peter Hinman

\section{Al Taylor}

I first met Jane Kister when she came to Ann Arbor from Oxford in the late 1970s. She had met my colleague from the Michigan mathematics department, Jim Kister, when he visited Oxford in 1977-78. They fell in love, married, and Jane moved to Ann Arbor, where she accepted a position as an executive editor at Mathematical Reviews (MR). While Jane was regularly in the Michigan math department as an active member of the logic seminar, I didn't have much contact with her until I became a member of the Mathematical Reviews Editorial Committee in 1989. Then, over the next sixteen years, at numerous meetings in various parts of the volunteer leadership of the AMS, as well as in occasional visits to the MR building, I saw her quite regularly. After starting as an associate editor at MR in the 70s, by 1989 , Jane was in a senior position in the management at MR. Even then, as throughout her career at MR, she kept close to mathematics by doing some mathematical editorial work and by participating in the logic seminar at Michigan. The year 1989 was also a time when the management structure at MR was changing and crucial questions about the future of MR were under consideration. Mathematical Reviews as a paper journal had been getting larger and more expensive as the mathematical literature expanded. As subscriptions became more expensive, the number of subscriptions was decreasing, and it was clear changes were going to be necessary. Throughout the next decade and beyond, Jane

Al Taylor is professor emeritus of mathematics at the University of Michigan. He was chair of the Mathematical Reviews Editorial Committee (19891992, 2002-2005) and associate treasurer of the AMS (1993-2002). His email address is taylor@umich.edu. played a key role at MR in helping to facilitate and manage the successful evolution of MR from a paper journal to an online database. While in retrospect it seems clear that this was the right choice, it was not always so clear, especially if you were an MR employee who was worried about keeping a job. From my interactions with many MR employees over the years, I know that MR enjoyed great employee loyalty and dedication to its goals. I think that much of this was due to Jane's ability to relate closely with MR staff and the way she cared for all in her circle. Her quiet and compassionate treatment of all she met enabled her to succeed as a manager at MR.

Jane's role as associate executive editor was also very important when the executive editor position changed, as it frequently did. At that time, executive editors were recruited from the outside mathematics community. They often brought new ideas that helped MR evolve. However, it was still necessary to do all the daily work at MR, the work of some 70+ employees. Mathematicians from academia didn't come with this knowledge or experience. I always thought it was Jane Kister and her team of long-time managers who kept the operations functioning smoothly throughout these changes at the top. The same was true when other big changes were happening at MR, such as the move from handling mathematical articles on paper to online editing. A huge internal change at MR was necessary to handle the expanding mathematics literature in a digital world.

MR has come a long way, from information typed on file cards to the current database with its rich links and searchability. It is the work of many people over many years, but Jane Kister is one whose work contributed enormously to this successful transition.

We miss her smile, her gentle laugh, and her quick wit that always made each meeting a little better.

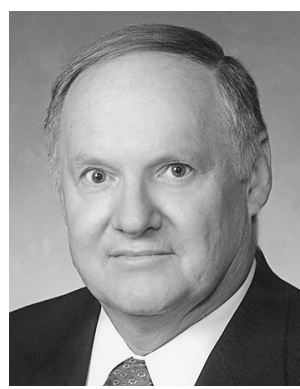

Al Taylor 


\section{John Ewing}

Jane Kister became the seventeenth executive editor of Math Reviews in July 1998. She had been at Mathematical Reviews for nearly twenty years before that, playing a key role in almost every part of its development-digitizing the database, computerizing operations, expanding coverage, and more. During that time, she worked with several dozen associate editors, five different executive editors (who headed MR), and three different executive directors (who headed the AMS). I was her third.

When Jane began in 1979, Math Reviews was just emerging from turmoil-large backlogs, new systems, too many new associate editors. Jane was stability; she was support; she was exquisite attention to detail. She remained all of these things for the next quarter century.

When I offered the position of executive editor to Jane in 1998, Math Reviews wasn't facing turmoil, but it was facing many pressures, both inside and out. Launched only a few years before, MathSciNet required a change to MR's operations, which were still fundamentally built upon a workflow geared towards a paper publication. We needed to speed up the process, gently but decisively. MathSciNet itself faced competition in a new world of online products with rapidly evolving business models. We needed a spokesperson-an expert in MR who also knew how to talk to mathematicians. Jane fulfilled all these needs.

During her tenure, every aspect of Math Reviews improved. The vast majority of reviews, which were previously submitted on paper, now came in online; the time to publication decreased dramatically; MR added new tools like MR Lookup and MRef; it included links to original publications for the first time; and Math Reviews began to create a citation database from reference lists. At the same time, relations with the broad mathematics community, including Zentralblatt, steadily improved.

When I considered her appointment as executive editor, Jane was a twenty-year veteran of MR and fiercely loyal to the organization. Over the preceding years, Math Reviews and the rest of the AMS had not always maintained a harmonious relationship, with occasional clashes between executive directors and executive editors. I hesitated to appoint a "fiercely loyal" internal candidate but decided to take the risk.

At Jane's retirement celebration in 2004, I told a story: It seems two husky moving men were struggling with a grand piano lodged in a doorway. It was stuck despite all their pushing and pulling, and finally one said, "I give up; we'll never get this into the house." And the other looked up in surprise: "In? ... I thought we were trying to get it

John Ewing is president of Math for America. He was the executive director of the AMS (1995-2009). His email address is jewing@mathforamerica .org. out." I never felt Jane and I were pulling or pushing against one another-not once, not ever. We worked together and easily. Jane was an accomplished professional, who loved Math Reviews and who served the publication and the Society for more than a quarter century.

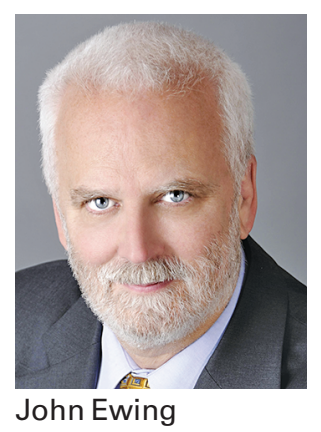

\section{Norman Richert}

I was hired by Jane in June 1999 with the title administrative editor. This was a title she held under several executive editors: Keith Dennis, Jerry Janusz, Bob Bartels, and Don Babbitt. The executive editorship was more of a rotating position in those days, and for many day-to-day purposes at Mathematical Reviews, she was effectively in charge.

Jane had an incredible depth of knowledge of the details and history of Math Reviews. She had strong opinions about how things should be, yet also allowed people a lot of freedom. In the editorial training that she gave me, I was certainly made aware of the importance of grammatical details. Things that I thought were small were very important to her. This made a big impression on me. At the university from which I came to Mathematical Reviews, I had developed a reputation as the nit-picky one, relative to written work. I discovered I had a long way to go in that department. Jane was always generous with her time with each executive editor that followed her. They would have lunch with her and pick her brain about history and context.

She was a very gracious and kind person, but also very proper. Around Christmas, there was always a delightful party for all the associate editors and managers hosted by Jim and Jane at their beautiful home. People dressed up; the food and wine were generous. Observing Jim and Jane interact with each other was heartwarming. The story of how Jane came to be at Math Reviews in Ann Arbor was the stuff of romantic movies.

The relationship between MR and the larger AMS was not always smooth sailing. But she would always urge the position that she thought was right and would stand up for what she thought was best for the staff. This was despite the fact that she thought there might be repercussions. I was

Norman Richert was managing editor at Mathematical Reviews. His email address is nrichert@comcast.net. 
always a little amused and saddened by that, since she was second to none in overall gravitas. Somehow, she never felt comfortable throwing her weight around.

Although she could be austere in her manner, Jane was notable for her kindness to all the staff. I am grateful to her for bringing me to Mathematical Reviews and for supporting me as I tried to get my mind around a very complicated operation.

It was a strange feeling when Jane announced her retirement, not only because she hired me, but because she seemed to embody the essence of what Mathematical Reviews was. It is a tribute to her leadership that she left a strong organization, with an outstanding and dedicated staff, that could move forward and grow, based on her vision.

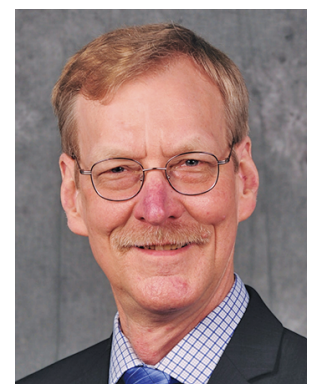

Norman Richert

\section{Credits}

Photo of Jane Kister is courtesy of the AMS.

Photo of Edward Dunne is courtesy of Edward Dunne.

Photo of Peter Hinman is courtesy of Karen Snyder.

Photo of Al Taylor is courtesy of the AMS.

Photo of John Ewing is courtesy of Thomas Stio.

Photo of Norman Richert is by Laurie DeWitt, Pure Light Images.

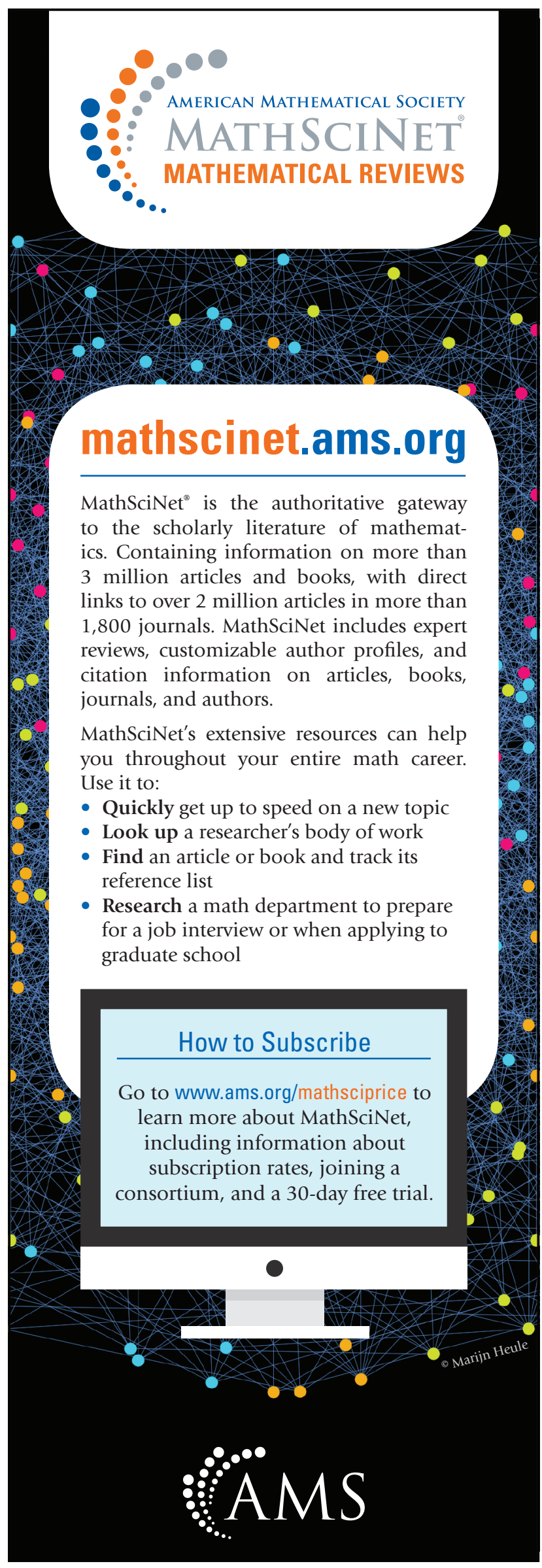

